\title{
Climate Change, Adaptive Strategies and Rural Livelihoods in Semiarid Tanzania
}

\author{
Richard Y. M. Kangalawe*, James G. Lyimo \\ Institute of Resource Assessment, University of Dar es Salaam, Dar es Salaam, Tanzania. \\ Email: *kangalawe@ira.udsm.ac.tz, lyimo@ira.udsm.ac.tz
}

Received October 23 ${ }^{\text {rd }}$, 2012; revised April $7^{\text {th }}$, 2013; accepted April 28 ${ }^{\text {th }}, 2013$

Copyright (c) 2013 Richard Y. M. Kangalawe, James G. Lyimo. This is an open access article distributed under the Creative Commons Attribution License, which permits unrestricted use, distribution, and reproduction in any medium, provided the original work is properly cited.

\begin{abstract}
Climate change is a global challenge to both sustainable livelihoods and economic development. In Tanzania as in most African countries, farming depends almost entirely on rainfall, a situation that makes agriculture and thus rural livelihoods especially in semiarid environments particularly vulnerable to climate change. This study analyses the impacts of climate change and variability on rural livelihoods with particular focus on agricultural production, food security and adaptive capacities in semiarid areas of Tanzania. The methods used in this study included focus group discussions, key informant interviews, household surveys and field observations. Results from the study indicate that communities understood climate change in terms of variability in rainfall patterns and amount, temperature patterns, wind, water availability, increased incidences of drought and decreased agricultural productivity. Communities in the study area acknowledged that while rainfall amounts have decreased over the last thirty years, temperatures have increased, an experience is also supported by meteorological data. Such changes were claimed to have reduced agricultural productivity particularly due to prolonged drought, inadequate and uneven distribution of rainfall as well as unpredictable onset and ending of rains. Stressors such as crop diseases and pests, low soil fertility and inadequate extension services were also reported to contribute to the decline in agricultural productivity and re-occurrence of food insecurity. In response, communities have developed multiple adaptation strategies, including growing of drought tolerant and early maturing crop varieties, increasing wetlands cultivation, water harvesting for small-scale irrigation and livestock keeping. However, households with limited livelihood assets are more vulnerable to the impacts of climate change and food insecurity. The study argues that diversification of adaptive strategies, such as water harvesting for small-scale irrigation, integration of livestock and crop production are crucial to ensuring sustainable livelihood in a changing climate.
\end{abstract}

Keywords: Climate Change; Adaptive Strategies; Food Insecurity; Rural Livelihoods; Semiarid Tanzania

\section{Introduction}

Studies done in different parts of the world have shown that there is a wide agreement among the scientific community that climate variability and change is taking place with impacts on the people's livelihoods [1] and that various coping mechanisms have evolved and are still evolving in the various communities [1-3]. Africa is one of the most vulnerable continents to climate change and variability, a situation that is aggravated by the interaction of multiple stresses, occurring at various levels $[1,4]$. This is partly due to low adaptive capacity and higher reliance on natural resources, such as agricultural land, forests and water which are very sensitive to

*Corresponding author. changes affecting the environment. Some countries in Africa already face semiarid conditions that make agricultural production challenging, and climate change will likely reduce the length of growing seasons as well as force large areas of marginal agricultural potential out of production $[1,5,6]$. For instance food production assessment indicates that domestic food production has already declined by $10 \%$ in several of the sub-Saharan countries [5]. It has also been projected that a reduction in yield in some countries would be as much as $50 \%$ by 2020 , with small-scale farmers being the most affected [1]. Ecosystems, land use and livelihoods of local communities are among the aspects influenced by climate change and variability [4].

In most African countries agricultural production de- 
pends almost entirely on the rainy season, a situation that makes Africa particularly vulnerable to climate change. Increased droughts negatively affect food availability, as it happened in the horn of Africa and southern Africa during the 1980s and 1990s [1,7]. Many regions are likely to be adversely affected by climate change $[1,4]$, including the mixed arid-semiarid systems in the Sahel and the rangelands in parts of eastern Africa, the systems in the Great Lakes region of eastern Africa, the coastal regions of eastern Africa, and many of the drier zones of southern Africa [1,7]. With a temperature increase of $3^{\circ} \mathrm{C}$ alongside the global warming anomaly, about 250 - 550 million people may be at risk of hunger with more than half of these people concentrated in Africa and Western Asia [7]. Thus Tanzania with more than one-third of its land area in the semiarid environment faces the risks of negative impacts associated with climate change [8]. Given the poverty level and high dependence on agriculture and natural resources, the country may be quite vulnerable to future climatic changes [9]. Agriculture is the main source of employment and livelihood for more than two thirds of the Tanzanian population, and the most important economic sector in terms of food production [10]. However, according to URT [11] most of the agricultural production is rainfed, a situation which makes it more vulnerable to climate change and variability. The impacts of climate change in agriculture include decreased production of different crops mainly associated with recurrent droughts, floods, increasing crop pest and diseases and shift of growing seasons [8,11]. For instance, the severe droughts of 1994-1996 and 2005/2006 which hit most parts of the country led to acute food shortages, food insecurity, water scarcity, hunger and acute shortage of hydropower [11].

An analysis of climate trends reveals that climate change poses significant risks for Tanzania. While projected changes in precipitation are uncertain, there is a high likelihood of temperature increases which may have variable impacts on different sectors. Climate change scenarios across multiple general circulation models show increases in country average mean temperature. Predictions show that the mean daily temperature will rise by $3^{\circ} \mathrm{C}-5^{\circ} \mathrm{C}$ throughout the country and the mean annual temperature will rise by $2^{\circ} \mathrm{C}-4^{\circ} \mathrm{C}$. Predictions further show that areas with bimodal rainfall pattern will experience increased rainfall of $5 \%-45 \%$ and those with unimodal rainfall pattern will experience decreased rainfall of $5 \%-15 \%$ [11,12]. In most parts of the country rains are increasingly declining and cycles are detrimentally changing. Already the frequency and intensity of extreme weather events such as drought and floods have increased affecting climate sensitive sectors such as agriculture [10]. Various studies done in Tanzania have shown a general increase in temperature over the last 30 years as well as decreasing rainfall over the same period in most parts of the country [13-15]. The sectors potentially impacted by climate change among others include agriculture, forestry, wildlife, water resources, coastal resources, wetlands and livestock, human health, energy, industry and transport [9]. Livestock is at risk with animals dying alongside deteriorating pasture condition and drying water sources. Tanzania's National Adaptation Programme of Action (NAPA) has ranked agriculture as top in the list of sectors whose dependent population is most vulnerable to foreseeable climate change [11].

It is in this context that this study was conducted to establish the climate change impacts in various sectors and agro-ecosystems and determine how vulnerable local communities are coping and/or adapting to associated risks. The main objective of this study was to assess the impacts of climate change and variability on rural livelihoods with particular focus on agricultural production, food security and existing adaptive capacities in the semiarid areas of Tanzania.

\section{Methodology}

\subsection{The Study Areas}

The study was carried out between February and June 2008 in Shinyanga and Singida regions both located in the semiarid zone of Tanzania. One district from each region was selected representing districts that had often experienced food insecurity. The corresponding districts involved in this study were Shinyanga Rural and Manyoni district for Shinyanga and Singida regions respectively. Two villages were selected from each of the districts, namely Ibingo and Ng'wang'hosha in Shinyanga Rural and Kitopeni and Mvumi in Manyoni (Figure 1).

Manyoni district lies between $6^{\circ} 7^{\circ} \mathrm{S}$ and $34^{\circ} 35^{\circ} \mathrm{E}$ covering an area of $28,620 \mathrm{~km}^{2}$ that is about $58 \%$ of the entire area of Singida Region. It lies within the semiarid areas of Tanzania where there are frequent food shortages due to uncertainty of rainfall [16]. Thus the area provides an opportunity to study impacts associated with community livelihoods. Climatically, Manyoni District has a unimodal rainfall regime, which spans from November to April. The long-term mean annual rainfall is $624 \mathrm{~mm}$ with a standard deviation of $179 \mathrm{~mm}$. The longterm mean number of rainy days is 49 with a standard deviation of 15 days. Generally rainfall in the District is low and unreliable. Temperatures vary according to altitude. The annual mean, maximum and minimum monthly temperatures in the District are $22^{\circ} \mathrm{C}, 24.4^{\circ} \mathrm{C}$ (November) and $19.3^{\circ} \mathrm{C}$ (in June) respectively [17]. The 2002 population and housing census show that Manyoni district had a total population of 204,482 people with a growth rate of $2.7 \%[18]$. 


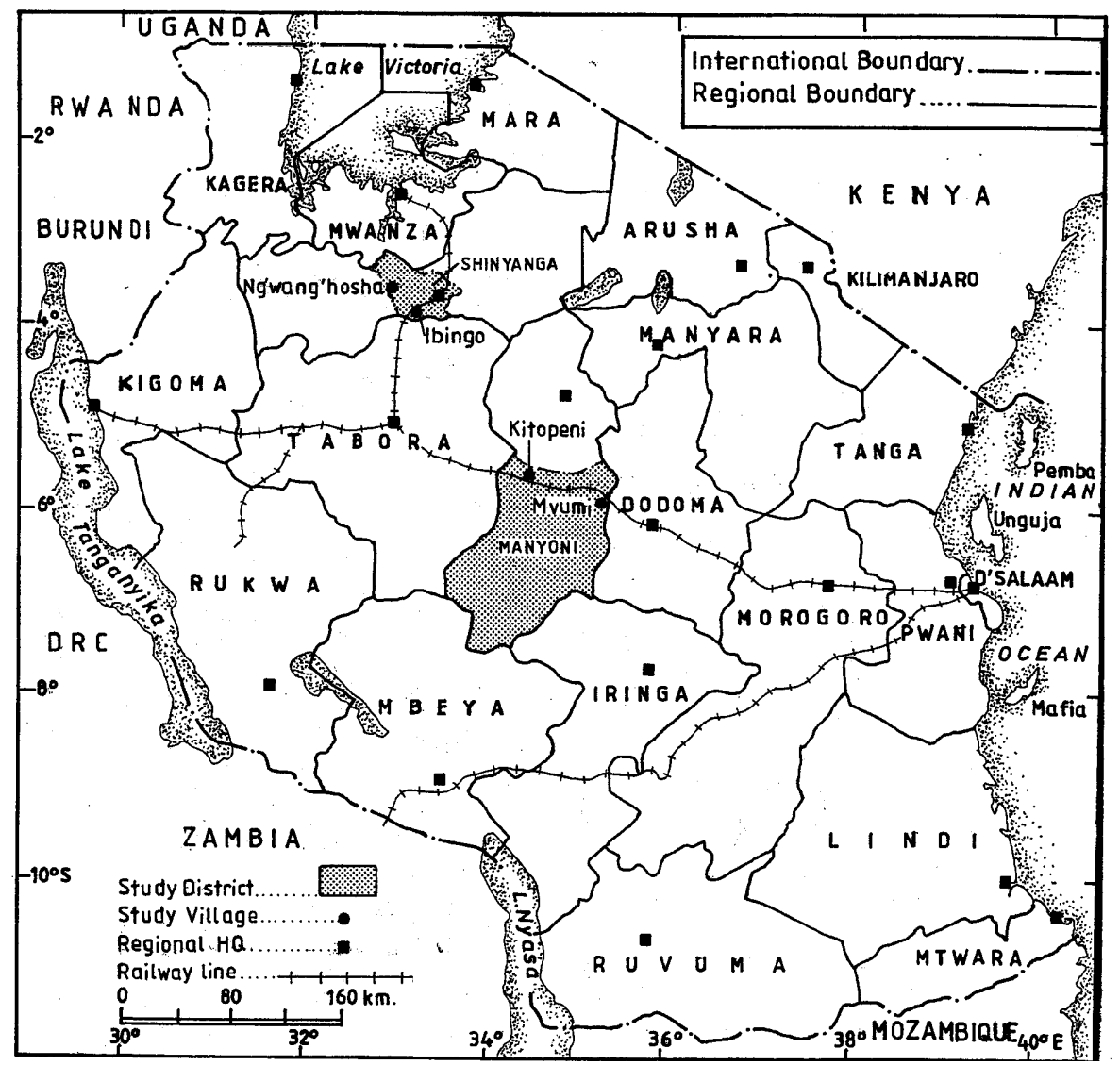

Figure 1. Map of Tanzania showing the location of the districts (shaded) and villages studied.

Shinyanga Rural district lies between $31^{\circ}$ and $35^{\circ} \mathrm{E}$ and $2^{\circ} 30^{\prime}$ and $4^{\circ} 25^{\prime} \mathrm{S}$, covering an area of $8906 \mathrm{~km}^{2}$. The district borders Kishapu in the east, Kahama in the west, Geita and Kwimba districts in the north, and Igunga and Nzega in the south. The long-term mean annual rainfall is between 750 and $900 \mathrm{~mm}$ that is received from midOctober to December and then February to mid-May [19]. The dry season occurs between mid May to mid-October. During such period the soils are hard to cultivate, pasture becomes very poor in quality and quantity and availability of water for domestic use and livestock become an acute problem. The temperature ranges from $12.9^{\circ} \mathrm{C}$ between June and October and $34.7^{\circ} \mathrm{C}$ between January and mid-March. According to the 2002 population and housing census Shinyanga Rural district had a total population of 276,393 people [18].

\subsection{Data Collection and Analysis}

In this study different methods and techniques were used to collect qualitative and quantitative data from both primary and secondary sources. Secondary data were obtained from reviews of both published and unpublished literature from various sources. Results from these reviews have been used to support various aspects related to the study. Primary data sources included structured and semi-structured interviews for households and key informants respectively, participatory assessments and physical observation.

Participatory methods included focus group discussions and key informant interviews at village level and district level. This was aimed at capturing the diversity of livelihood activities that reflect adaptive capacity and extent of community vulnerability to climate change. The participatory methods were used to establish among others the perceptions of climate change and its influence on food security, existing adaptive capacities and extent of vulnerability of local communities to climate change. The focus group discussion comprised of 12 - 15 people representing various livelihoods and age groups in each village. The key informants were drawn from district officials, extension workers and elderly people in the respective villages. Physical observations were also made in the field to capture and crosscheck issues raised in the focus group discussions and key informant interviews, such as crop production and food situation in the respective areas.

Household interviews were conducted using structured questionnaires to complement the more qualitative information from participatory assessment and from documentary sources. A sample of $5 \%$ of the village house- 
holds was randomly selected for interviews with equitable representation from all sub-villages in the respective village. A total of 96 households were selected, including $61.5 \%$ and $38.5 \%$ male and female respondents respectively. The age of respondents ranged between 19 and 90 years.

Qualitative data analysis was done through triangulartion of narratives from focus group discussion, key informant interview and evidence from field observations. The summaries of the narrations are used in the discussion in subsequent sections. Quantitative data were coded, processed and analysed using Statistical Package for Social Science (SPSS). Frequency distribution and cross tabulation were used to compare different variables within and across villages. Climatic data such as rainfall and temperature were analysed using Excel to generate graphs showing patterns of various aspects of changing climate.

\section{Results and Discussion}

\subsection{Local Awareness and Perceptions of Climate}

Results from this study indicate that communities have a clear understanding of climate change. The concept "climate" is perceived differently at different levels of conceptualization. Discussion with stakeholders at the village level in the study areas has shown that people understand climate as, among others, rainfall, drought, temperature, wind and floods (Figure 2). At the regional and district levels it is perceived as dynamics in weather conditions that cause changes and/or variability in rainfall patterns, temperature patterns, wind velocity, surface and ground water regimes. Such changes are perceived to lead to years of prolonged drought or unpredictable excessive rainfall often associated with decreased agricultural productivity. The majority of the respondents (76\%) had attained primary education, hence they had a broad understanding of the linkages between climate change and various livelihood issues.

Figure 2 shows that drought and rainfall ranked the highest among the aspects mentioned to indicate the local understanding of climate, as reported by $91.9 \%$ and 91.7\% of the respondents in Manyoni and Shinyanga, respectively. Concerns about drought were raised more in these districts because of the recurrent experiences of droughts, hence its local association with climate. Temperature was reported as the third aspect explaining climate change at the local level, a concern raised by $75 \%$ of the respondents. Other aspects such as floods and humidity were mentioned by smaller proportions of respondents, indicating that they are not a common occurrence.

In all the study areas there was a general feeling that rainfall pattern has been decreasing during the last 20 years as expressed by $81.3 \%$ of the respondents, hence their concern about droughts. This is an indication that rainfall is one of the parameters that may be seriously affected by changing climate. At the village level the concept "climate change" was associated with weather conditions particularly rainfall inconsistencies and unpredictability over years rather than actual change. Major concerns were related to indicators like reduced amounts of rainfall, rainfall coming late, increased temperatures and incidences of drought, variations in agricultural seasons and decreased crop productivity (Table 1).

The general community concern about decreased amounts of rainfall is supported by long-term rainfall data from Shinyanga meteorological station (Figure 3). About $7.3 \%$ of the respondents reported that rainfall has increased over the past few years. These could possibly be motivated by the extreme events such as El Niño that took place fifteen years ago. The increasing rainfall trend is evident in the meteorological data from Manyoni meteorological station (Figure 4), which shows a slightly increasing trend since 1985. This trend seems to support the concern of some of the respondents that rainfall is increasing. However, in both districts, rainfall exhibited considerable annual variations. Despite the slight increase since the mid-1980s, rainfall records from the early 1960s for Manyoni district show that there has been a steady decrease in amounts. Both patterns may imply a changing climate, with variable impacts on agricultural production and rural livelihoods as discussed in Section 3.2.

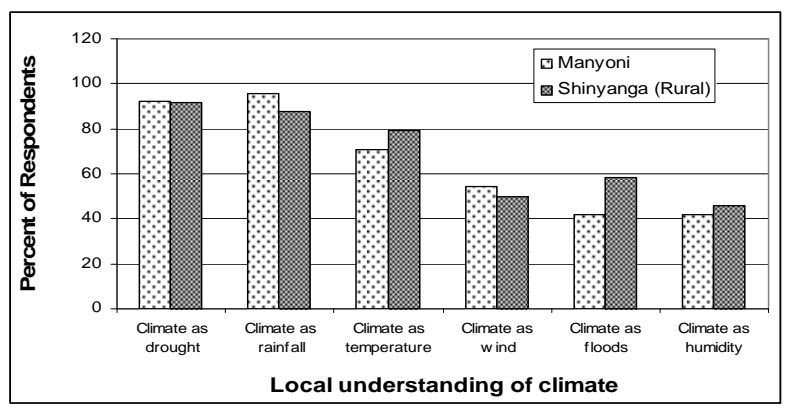

Figure 2. Local understanding of the climate in Manyoni and Shinyanga rural districts.

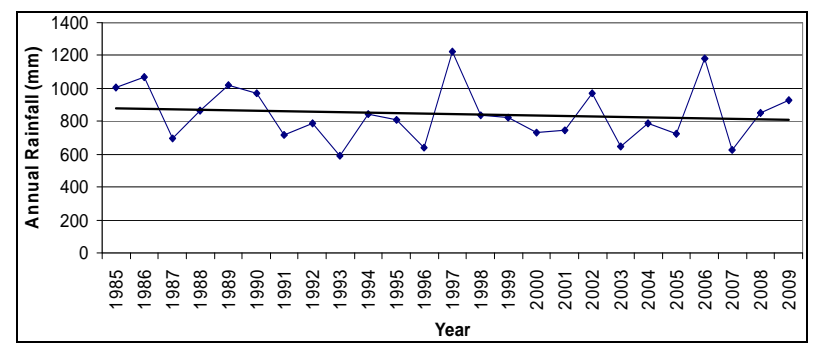

Figure 3. Annual rainfall for Shinyanga district (19852009). 
The locally perceived increase in the amount of rainfall for Manyoni district concurs with projections that with climate change some parts of the country will receive increased amounts of rainfall [20]. The projected and/or experienced increase in rainfall could be associated with the locally reported increase in crop productivity as one of the indicators of climate change (Table $\mathbf{1}$ ).

The monthly rainfall is also highly variable (Figure 5).

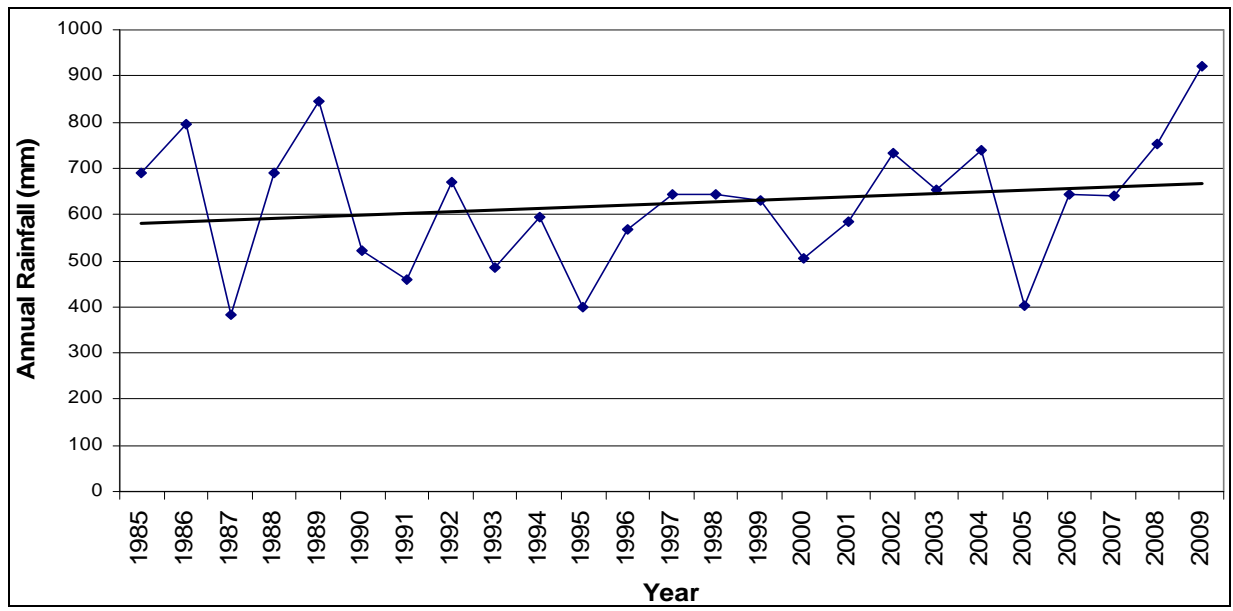

Figure 4. Annual rainfall for Manyoni District (1985-2009).
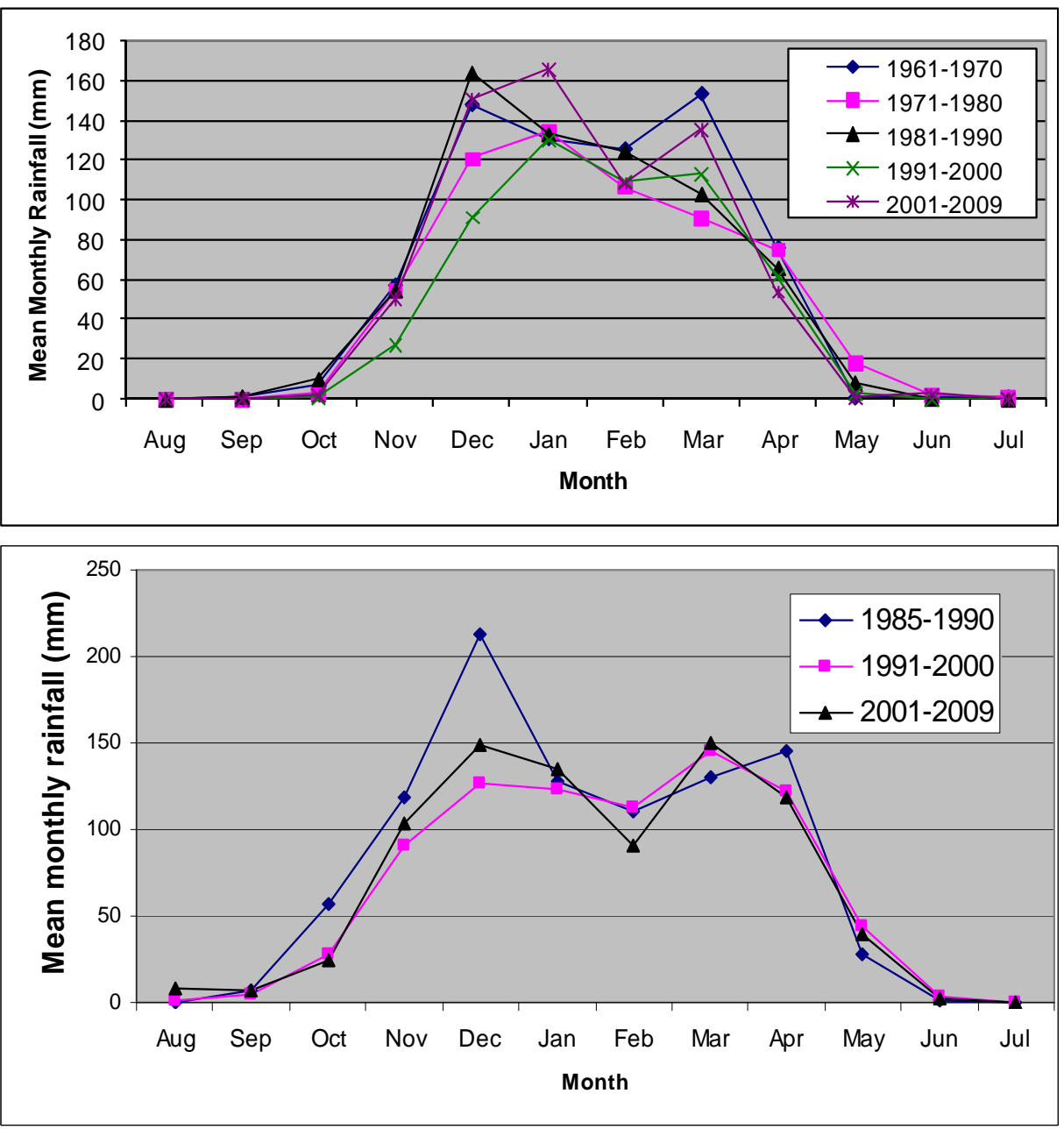

Figure 5. Mean monthly rainfall for Manyoni (top) and Shinyanga (bottom) meteorological stations. 
Table 1. Percent responses on local indicators of climate change.

\begin{tabular}{|c|c|c|c|}
\hline \multirow{2}{*}{ Local indicators of climate change } & \multicolumn{2}{|c|}{ District } & \multirow{2}{*}{ Total } \\
\hline & Manyoni & Shinyanga (Rural) & \\
\hline Rainfall coming late in seasons & 83 & 83 & 83 \\
\hline Increased incidence of drought & 83 & 67 & 75 \\
\hline Decreased crop productivity & 88 & 54 & 71 \\
\hline Outbreak of human diseases & 67 & 67 & 67 \\
\hline Outbreak of livestock diseases & 67 & 67 & 67 \\
\hline Outbreak of plant diseases & 67 & 67 & 67 \\
\hline Increased temperature & 58 & 58 & 58 \\
\hline Shortened growing seasons & 58 & 54 & 56 \\
\hline Re-occurrence of food shortage & 58 & 50 & 54 \\
\hline Rainfall coming too early in the season & 50 & 54 & 52 \\
\hline Increased rainfall amount & 42 & 63 & 52 \\
\hline Decreasing number of livestock & 54 & 38 & 46 \\
\hline Increased crop productivity & 29 & 54 & 42 \\
\hline Changes in types of livestock & 25 & 33 & 29 \\
\hline Emergency of new plant species & 21 & 33 & 27 \\
\hline Emergency of new animal species & 13 & 29 & 21 \\
\hline
\end{tabular}

Source: field survey 2008.

The mean monthly rainfall in Manyoni was more evenly distributed during the period 1971-1980 and 1981-1990, while it was more variable in other periods (Figure 5). In Shinyanga, the monthly rainfall was more evenly distributed during the period 1991-2000 compared to other periods. However, in both study areas the rainfall peaks are recorded in January-December and in March, with a dry-spell in February. Inadequate rainfall during this critical crop growing season may have had considerable negative effects on crop production, leading to the general local concern that rainfall amounts have decreased over time.

The remaining $11.5 \%$ of the respondents were of the opinion that rainfall patterns have not changed during the last few years. Their response could be associated with little experience of the long term rainfall patterns of these areas, especially for the inhabitants who have settled in the study area only recently. Table 2 shows that only about $43 \%$ of the respondents were born in the studied villages. The $57 \%$ in-migrant respondents could be limited in their understanding of the local environments in the villages they are found today.

It was generally acknowledged that while rainfall amounts have decreased considerably over the last twenty to thirty years, temperatures have increased. About $81 \%$ of the households claimed that their areas have been generally warmer while $19 \%$ of respondents reported that the area has been cooler (Figure 6). Temperature records for Shinyanga meteorological station show that there has been a steady temperature increase since the mid-1980s (Figure 7), which concurs with the majority local perceptions. Temperature records for Manyoni could not be obtained; however, data from a neighbouring station, Dodoma, with similar semiarid agroecological conditions have been used to present proximate conditions (Figure 8), as it shows similarly increasing trends.

\subsection{Implications of Climate Change on Rural Livelihoods}

While climate change is a global phenomenon, people will be differently affected by its local impacts. Among other impacts, changing temperature and precipitation patterns will have a profound impact on the natural resource base world-wide, and on the income and livelyhoods of people that depend on these resources [1]. Economic analysis of these local impacts of climate change need to be undertaken to establish how local natural resources will be affected in terms of productivity, dynamics and, subsequently, how local income and livelihoods will be influenced as a function of changes in resource availability, changes in demand for resources and adaptation options, among others [21-23]. 


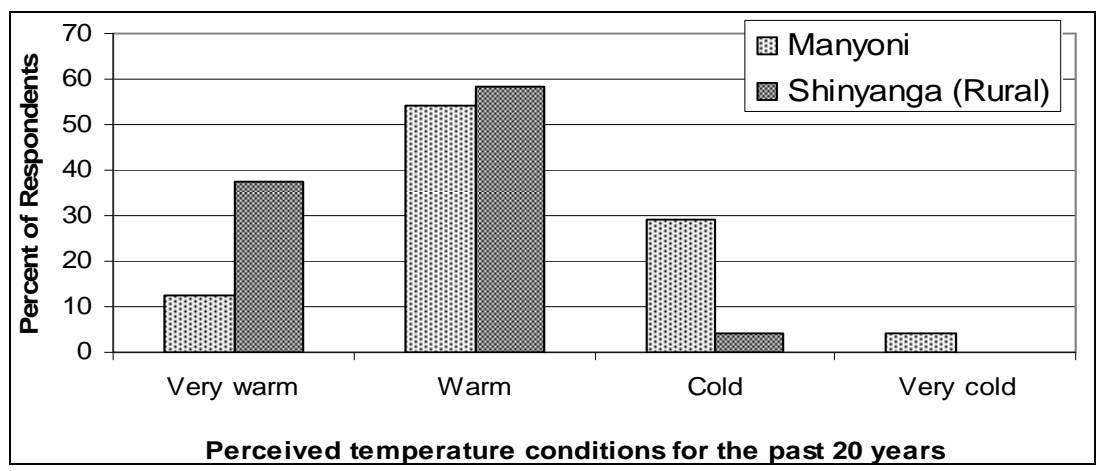

Figure 6. Local perception of temperature conditions for the past 20 years in Shinyanga Rural and Manyoni Districts.

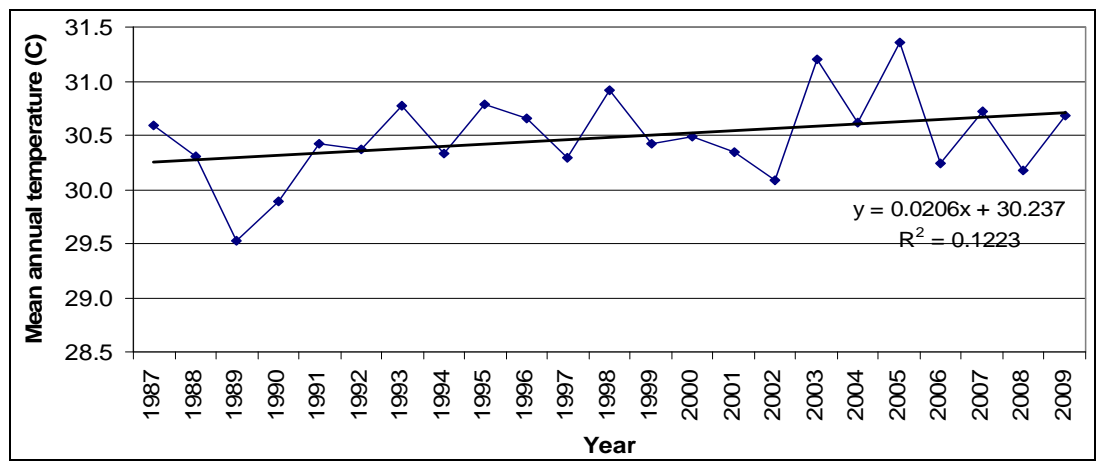

Figure 7. Mean annual temperature for Shinyanga meteorological station (1987-2009).

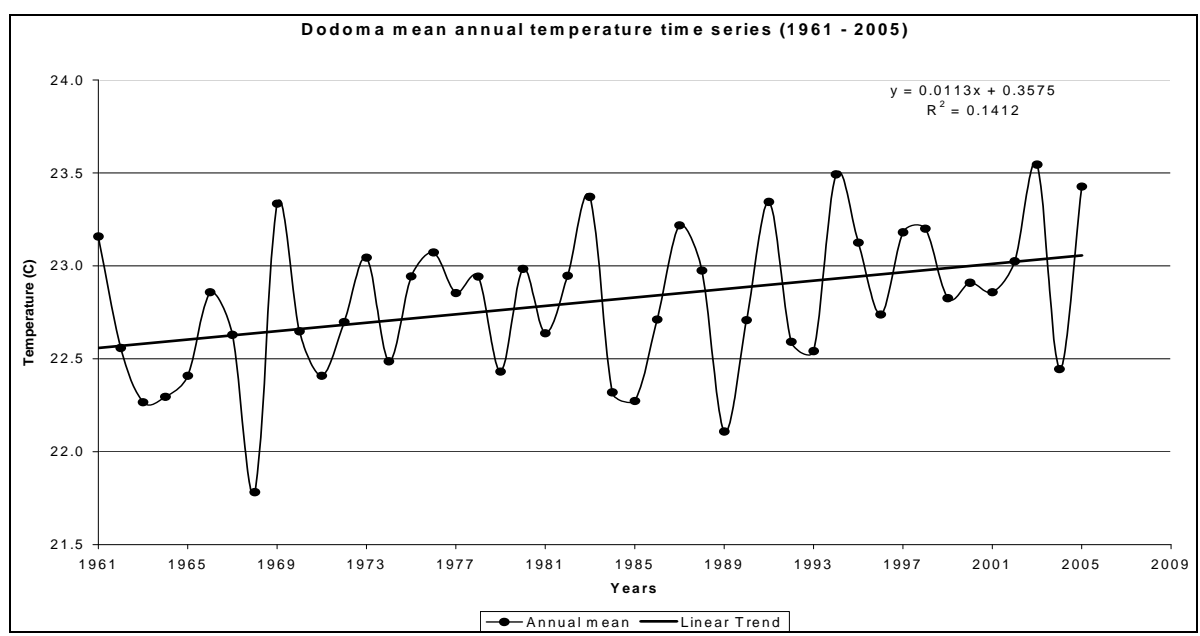

Figure 8. Mean annual temperature for Dodoma (1961-2005). Source: Andresen et al. (2008).

Table 2. Percentage responses on places of origin of the respondents.

\begin{tabular}{|c|c|c|c|c|c|}
\hline \multirow{2}{*}{ Places where born } & \multicolumn{2}{|c|}{ Manyoni } & \multicolumn{2}{|c|}{ Shinyanga Rural } & \multirow{2}{*}{ Total } \\
\hline & Kitopeni & Mvumi & Ibingo & Ng'wang'hosha & \\
\hline Born in the village & 14.3 & 60 & 59.3 & 42.9 & 42.7 \\
\hline Born outside the village but within the district & 53.6 & 40 & 22.2 & 23.8 & 35.4 \\
\hline Born outside the district but within the region & 28.6 & 0 & 3.7 & 23.8 & 14.6 \\
\hline Born outside the region & 3.6 & 0 & 14.8 & 9.5 & 7.3 \\
\hline Total & 100 & 100 & 100 & 100 & 100 \\
\hline
\end{tabular}


In Tanzania the agricultural sector is central to sustainable development, as it is the mainstay of over $75 \%$ of the population, accounting for $45 \%$ of the GDP, and is vital for ensuring food security and alleviating rural poverty. Thus assessing vulnerability of agriculture to climate change and planning adaptation interventions is crucial for sustaining rural livelihoods. Agriculture, including both crop and livestock production, is the major livelihood activity in the studied villages, other activities being trading various commodities, such as crops, petty businesses and casual labour (Table 3). This section focuses more on the agriculture, which is the major source of livelihoods for most people of the study area.

\subsubsection{Implications of Climate Change on Agriculture}

Agricultural productivity was reported to have declined in both study areas, mainly due to natural factors such as drought and strong winds, and in some instances also due to floods as was the case during El Niño events. The implications of climate variability/change was assessed in terms of crop productivity trends for both food and cash crops, changes in types of crops produced, farming systems, and patterns in agricultural related activities, incidences of crop pests and diseases.

Respondents were asked during household interviews about the types of crops they produced. The study findings show that a diverse set of crops is grown in the studied districts. However, in both districts crop productivity was reported to be declining. The respondents were also asked to indicate whether there are crops that had been abandoned. Respondents in Manyoni indicated that they had abandoned Bambara nuts, beans and bulrush millet. In Shinyanga Rural District it was also reported that local maize varieties have been abandoned.

The reasons advanced for changes in types of crops produced varied between places. However, it appeared that the major cause for a decline in production of maize was drought. Other crops that were reported to have been affected by drought conditions were finger millet, beans, cowpeas and groundnuts, mainly due to shortened growing seasons associated with drought incidences. Discussions with extension workers in the area confirmed the observations from the local farmers. Untimely supply of drought tolerant crop seeds was mentioned as a factor for some farmers abandoning crops that cannot perform well under conditions of changing climate.

The decline in the production of crops such as cowpeas and groundnuts was also reported to be associated with drought conditions and crop diseases. Other causes included a decline in soil fertility. This could be attributed to continuous cropping of the same pieces of land or to the increasing temperatures that increase the rate of organic matter decomposition. Scientific research seems to support local people's concern about the shortening of the growing season in parts of central Tanzania, in which Manyoni district is a part [20]. It is argued that warmer temperatures lead to accelerated phenology, shortening the growing season which consequently reduce potential crop yield [20]. Thus warmer temperatures in combination with reduced rainfall lead to declining yields.

Another type of change recorded for Shinyanga was the shift from growing cotton to sunflower due to drought and increased incidences of crop pests and diseases. The high prices of agro-chemicals and low prices for the crop at the market have forced some farmers to shift to other crops. It was further reported in Shinyanga Rural district that chickpea production has increased due to favourable climatic conditions for this crop and the availability of ready markets as indicated by about $3 \%$ of the respondents.

As noted in the previous discussion, almost all households are involved in crop production as their main source of livelihood. This suggests that when such activities are impacted by climate change it may have serious consequence on household food security and general livelihoods. Thus involvement in other economic activities besides agriculture strengthens the household adaptive capacity when agriculture is negatively affected. Such activities complement each other in supporting household livelihoods.

Since agriculture in Tanzania is predominantly rain-fed, it is anticipated that where the frequency and intensity of droughts increase, this will affect agricultural production, thereby severely reducing the supply of

Table 3. Main livelihood activities in the study area.

\begin{tabular}{|c|c|c|c|c|c|}
\hline \multirow{2}{*}{ Livelihood activities } & \multicolumn{2}{|c|}{ Manyoni } & \multicolumn{2}{|c|}{ Shinyanga Rural } & \multirow{2}{*}{ Total } \\
\hline & Kitopeni & Mvumi & Ibingo & Ng'wang'hosha & \\
\hline Crop cultivation & 100.0 & 95.0 & 100.0 & 100.0 & 99.0 \\
\hline Livestock keeping & 57.1 & 35.0 & 63.0 & 57.1 & 54.2 \\
\hline Crop trading & 32.1 & 15.0 & 25.9 & 28.6 & 26.0 \\
\hline Casual labour & 21.4 & 25.0 & 25.9 & 28.6 & 25.0 \\
\hline Petty business (e.g. kiosks, food vending) & 32.1 & 5.0 & 25.9 & 19.0 & 21.9 \\
\hline
\end{tabular}


various crops. In addition, a decrease in amounts of rainfall, increased evapo-transpiration associated with increasing temperatures and seasonal unpredictability will have serious consequences on crop yields, shifts in agrodiversity, and increased outbreaks of pest and diseases. Hussien et al. [24] report, for instance, that increased moisture stress has been found to result in the emergence of new weed species in Ethiopia, such as the parasitic Alectra vogelii attacking groundnuts. Severe infestation with this new weed species was observed in groundnuts in the Erer valley, with a subtropical subhumid climate showing moisture stress. Thus the problem of weeds is likely to be compounded under changing climate which is likely and already causing increased moisture stress especially in the dryland areas. A decrease in agrodiversity compounded by climate change will have severe consequences on food security as it usually is an insurance in events of drought and pest attacks [25]. Climate change results in increased water scarcity, reduced river flows and water storage, which seriously affect crop production, especially of irrigated crops like rice.

\subsubsection{Incidences of Insect Pests, Diseases and Vermin}

About $71 \%$ of the respondents indicated an increase in incidences of crop pests. In Manyoni district, for instance, the most serious pests reported were weevils, birds, stalk borers, large grain borers, and vermin such as rodents, monkeys and wild pigs. In Shinyanga (Rural) district the crop pests of major concern include cotton stainers, cutworms and armyworms. Concerning pests, a considerable proportion of respondents (42\%) reported that there are new and emerging pests in their areas. The emerging pests in these districts included rodents, armyworms, bollworms, stalk borers, larger grain borers and leaf hoppers. It should be noted, however, that though these pests were mentioned by some farmers as emerging pests, it does not necessarily imply that these pests were completely absent from the area in the past. It could possibly be that the incidences of such pests have increased. What is commonly known in the literature is that with changing climate there are increased incidences of crop pests and diseases [13,20,26,27]. Maina and Lale [28] report, for instance, that the survival of some stored product insect pests such as Callosobruchus maculatus of cowpeas is influenced by temperature and humidity, where these factors set the lower and upper limits for egg laying and progeny development in populations of this insect pest. In addition, the proportion of eggs that develop to adulthood is significantly lower in the cold seasons than in the hot or rainy seasons. What is yet to be confirmed, however, is whether the increase in such incidences at local level is due to climate change/variability or other factors.

\subsubsection{Impact of Climate Change on the Livestock Systems}

Livestock production is one of the production systems that are potentially vulnerable to climate change/variability. Respondents in this study indicated that due to low rainfall conditions, pastures have decreased significantly leading to low livestock production in terms of calves, milk and meat. A similar observation was also reported by Kangalawe et al. [29]. In addition, since rainfall seasons have increasingly been unpredictable, pastures have become inadequate as compared to previous years. As a result livestock production is locally believed to have declined. It was asserted that because of the unfavourable pasture conditions the livestock do not have sufficient to feed on; they are generally weak and may not breed as efficiently as would do under favourable conditions. Generally, shortage of pastures due to changing climate may result in competition for available land, causing conflict and insecurity.

Warmer temperatures lead to vegetation drying faster and drinking water becoming scarce much faster after the end of the rainy seasons. Furthermore, livestock forage productivity and palatability may decline as plant composition changes due to increased temperature and reduced rainfall. In addition, livestock diseases become more frequent with climatic extremes. As such livestock forage amount and quality may decline as rangeland plant composition changes due to temperature, rainfall and $\mathrm{CO}_{2}$ concentrations. Climate projections indicate that droughts impact faster and may have more severe consequences on livestock, wildlife and people. One of the possible risks is that livestock and human diseases will be more frequent with climatic extremes. Already human diseases such as highland malaria and cholera have become more prevalent in several parts of Tanzania and East Africa, for example in the Lake Victoria basin $[13,26,27]$. Cholera epidemics for instance are associated with the anomalously warm and wet El Niño years, such as the situation that prevailed in 1982 and 1997 [26]. In Shinyanga, for example, incidences of livestock diseases like bloody diarrhoea, black quarter and foot and mouth disease were reported by respondents to have become a common phenomenon. High concentrations of livestock and wildlife in the fewer areas with ample pastures and water within the semiarid environment, e.g. wetlands and forests, may also lead to land degradation, for example, through overgrazing and deforestation.

Due to shortage of pastures and water associated with the changing climate, seasonal migration of livestock has been intensified in search for water and pastures. Socioeconomically, such migrations were reported by respondents in this study to affect children who fail to go to school because of travelling long distances looking for pastures and water for the livestock. Among the destina- 
tions for the livestock migrating from places like Shinyanga have been Singida, Dodoma, Tabora, Mbeya, Iringa and Morogoro regions. Studies elsewhere have shown that this has had considerable environmental and socio-economic consequences [29-31], including land degradation and destruction of water catchments in recipient areas. Degradation of water catchments, e.g. through deforestation may be responsible for increased carbon emission, which further influences climate change. In many developing countries particularly in Africa loss of forestry because of deforestation and forest degradation arising from farming activities, timber logging and fuelwood collection is considered to be the primarily cause of green house gas emission [32]. Tropical deforestation is estimated to contribute about $25 \%$ of the net annual $\mathrm{CO}_{2}$ emissions mainly from slashing and burning of high-biomass vegetation and decomposition of soil organic matter [33].

\subsection{Community-Based Adaptation Strategies to Impacts of Climate Change and Variability}

In response to changing climate, communities in the studied villages have developed multiple strategies to adapt to changing environmental conditions. For instance, adaptation to drought conditions is achieved through various methods, including the growing of drought tolerant and fast maturing crop varieties, buying food, increasing wetlands cultivation and livestock keeping, and where feasible, water harvesting, buying supplementary foods, practicing mixed cropping and increased emphasis on small stocks (Table 4). Households with limited livelihood assets were seen to be more vulnerable to the im- pacts of climate change, especially on food insecurity, because of limited adaptive capacities.

\subsubsection{Emphasis on Drought Tolerant Crop Varieties}

Cultivation of drought and/or pest tolerant crops varieties is one of the local adaptation strategies to the impacts of climate change, especially those associated with unreliable and unpredictable rains. As indicated in Table 4, about $98 \%$ of the respondents considered growing of drought tolerant crops varieties as an important mechanism especially for addressing droughty conditions. This points to a long experience with drought conditions to the extent that nearly all community members understand the importance of using drought tolerant crops or crop varieties. As such most farmers have tried to adapt by planting several varieties of sorghum and other drought tolerant crops such as sweet potatoes and green grams.

In several instances rainfall was reported to have been received in amounts above average, and communities had to adapt to such eventuality. Under such situations the main adaptation mechanisms reported have included growing water demanding crops, such as rice (32.2\%), buying supplementary food (31.2\%) and constructing drainage ditches in farms (29.5\%). Only a small proportion (2.2\%) of the respondents reported migration outside their villages as a result of excessive rains affecting their local livelihoods. However, a few people (4.9\%) reported to have no adaptation mechanisms for excessive rainfall, mainly including the resource poor households. On the other hand, this may reflect the fact that in many instances excessive rainfall is not always viewed by the local communities as a major problem as compared to droughts.

Table 4. Percentage responses on community adaptation to drought conditions.

\begin{tabular}{|c|c|c|c|}
\hline Adaptation mechanism & Manyoni & Shinyanga (Rural) & Total \\
\hline Growing drought tolerant crops & 100 & 95.8 & 97.9 \\
\hline Growing fast maturing crops & 66.7 & 75 & 70.9 \\
\hline Buying supplementary foods & 66.7 & 62.5 & 64.6 \\
\hline Crop diversification and mixed cropping & 37.5 & 50 & 43.8 \\
\hline Emphasis on small stocks (small animals) & 37.5 & 37.5 & 37.5 \\
\hline Reducing areas cultivated & 4.2 & 41.7 & 23.0 \\
\hline Emphasis on livestock keeping instead of crops & 16.7 & 25 & 20.9 \\
\hline Seasonal migration of livestock keepers & 20.8 & 20.8 & 20.8 \\
\hline Irrigation (wetland cultivation) & 8.3 & 29.2 & 18.8 \\
\hline Distributing livestock herds in different places & 12.5 & 12.5 & 12.5 \\
\hline Rainwater harvesting & 4.2 & 16.7 & 10.5 \\
\hline Migrating to other places (permanently/temporarily) & 8.3 & 4.2 & 6.3 \\
\hline Growing non-traditional crops & 4.2 & 0 & 2.1 \\
\hline Early planting & 0 & 4.2 & 2.1 \\
\hline Casual labour & 4.2 & 0 & 2.1 \\
\hline
\end{tabular}




\subsubsection{Crop Diversification}

Several climate change coping and adaptation strategies have been identified in Manyoni and Shinyanga districts, including crop diversification (Table 4). The study argues that diversification and adaptive strategies such as water harvesting for small-scale irrigation, integration of livestock and crop production, and non-farm activities are crucial to ensure sustainable livelihoods in a changing climate. In the study areas, $46.7 \%$ of the respondents indicated to be entirely engaged in crop cultivation, involving a diversity of crop types. Crops are grown in diverse mixtures, aiming at increasing farm productivity and avoiding the risk of crop failures. Growing crops with different growth requirements ensures that even under stressful environments such as drought, some harvest can be obtained. Such experiences are also reported for other parts of semiarid Tanzania [34]. About 50.5\% practiced agro-pastoralism. A small proportion of respondents (6.6\%) reported to be involved with agro-forestry. The implication of these findings is that in semiarid environments livelihoods are diversified by combining crop production and livestock keeping and/or agroforestry, as well as various other non-farm activities. Crop diversification and livestock keeping are viewed as risk adverse strategies especially in semiarid environments [34-36].

\subsubsection{Wetland Cultivation}

Respondents close to wetlands reported to practice irrigation or wetland cultivation as a means of reducing the impacts of drought and high temperatures in the soil, since wetlands are relatively cooler and moister than upland fields. However, the poorly developed irrigation facilities limit this practice to only small plots. The proportion of respondents reporting this practice was relatively small (18.8\%), indicating that irrigation is not a common practice in the study areas. In some places, especially in these dryland areas, even wetland cultivation may not be so reliable in ensuring sustainable livelihoods especially if they dry up early in the season [31].

\subsubsection{Integration of Livestock in the Farming System}

In Manyoni and Shinyanga Rural Districts, as well as other semiarid environments it is traditional to keep large herds of livestock as a sign of wealth and as a status symbol. It is for these reasons that many farmers in such areas invest in livestock whenever they get resources from other economic activities [29,37,38]. While such a practice has guaranteed a livelihood for the respective households in times of crop failure due to unreliable climatic conditions and/or other factors, they have also been a cause for environmental degradation especially through overgrazing. Local experience shows, however, that as a result of climate change and its impact on the availability of pastures and water, many farmers now put more emphasis on small stocks whose fodder and water requirements are smaller, as expressed by $37.5 \%$ of the respondents. The small stocks include goats and sheep.

As a result of climate change, which has made crop production rather unpredictable because of variations in rainfall patterns, many farmers have put more emphasis on livestock keeping instead of crops, as reported by 20.9\% of the respondents (Table 4). Livestock are often sold in times of need. Selling of livestock appeared to be a major means of dealing with food shortages in Manyoni and Shinyanga Rural Districts, and appears to be a coping strategy closely associated with semi-aridity. The practice is also common in other parts of the semiarid areas in the country $[37,39]$.

\subsubsection{Diversification into Non-Farm Livelihood Activities}

Other adaptation strategies against changing climate reported in Manyoni and Shinyanga Rural Districts include seasonal migration of livestock keepers and distribution of livestock herds in different places; rainwater harvesting; and doing casual labour to be able to get food and other household needs. Other strategies include selling of livestock; timely planting; and engagement in small businesses, including shops, local restaurants and kiosks, selling of crop and livestock, among others. In particularly severe droughts some households in the studied communities reported to have invariably relied on relief food from government (Table 4). However, the efficacy of these measures is variable.

Generally, the diversity of the reported adaptation measures could be a reflection that one single adaptation strategy may not be sufficient for communities to be able to adapt to conditions of climate change/variability [39]. The complementarities attached to the diverse set of adaptation strategies are thus a crucial concern for the rural communities.

\section{Conclusions}

The study has shown that almost all households are involved in agricultural production as their main source of livelihood. This suggests that when agricultural activities are impacted by climate change it may have serious consequences on their households' food security and general livelihoods. Diversification to other economic activities besides agriculture strengthens the household adaptive capacity when agriculture is negatively affected. Such activities complement each other in supporting household livelihoods, which are particularly important in adapting to the changing climate. The observed decline in crop productivity in all the study areas is multifaceted, being partly due to impacts of changing climate and partly due to other non-climatic stress factors such as 
shortage of land, low soil fertility and inadequate extension services. Climatic related events such as rainfall coming late, increased temperature and increased incidences of drought have serious impacts on livelihoods and hence rank high among the factors affecting community livelihoods. However, there are variations from one district to another depending on the experience of related climatic events and adaptive capacities.

Various adaptation strategies are implemented at community level on an ad-hoc basis with limited planning. However, such strategies could lead to long-term sustainability if enhanced and well planned. The diversity of the reported adaptation measures indicates, however, that no single adaptation strategy may be sufficient for communities to be able to fully adapt to climate change. Thus the complementarities attached to the diverse sets of adaptation strategies are a crucial concern for the rural communities. However, there are needs for more information, education and a communication strategy on climate change issues affecting rural community livelihoods.

\section{REFERENCES}

[1] IPCC, "Climate Change 2007: Impacts, Adaptation and Vulnerability," Contribution of Working Group II to the Fourth Assessment Report of the Intergovernmental Panel on Climate Change (IPCC), Cambridge University Press, Cambridge, 2007.

[2] W. N. Adger, S. Huq, K. Brown, D. Conway and M. Hulme, "Adaptation to Climate Change in the Developing World,” Progress in Development Studies, Vol. 3, No. 3, 2003, pp. 179-195. doi:10.1191/1464993403ps060oa

[3] V. A. Orindi and A. L. Murray, "Adapting to Climate Change in East Africa: A Strategic Approach,” Gatekeeper Series 117, International Institute for Environment and Development (IIED), London, 2005.

[4] M. Boko, I. Niang, A. Nyong, C. Vogel, A. Githeko, M. Medany, B. Osman-Elasha, R. Tabo and P. Yanda, "Africa: Climate Change 2007: Impacts, Adaptation and Vulnerability,” In: M. L. Parry, O. F. Canzian, J. P. Palutikof, P. J. van der Linden and C. E. Hanson, Eds., Contribution of Working Group II to the Fourth Assessment Report of the Intergovernmental Panel on Climate Change, Cambridge University Press, Cambridge, 2007, pp. 433-467.

[5] G. Fischer, M. Shah, F. N. Tubiello and H. vanVelthuizen, "Socio-Economic and Climate Change Impacts on Agriculture: An Integrated Assessment, 1990-2080,” Philosophical Transactions of the Royal Society B, Vol. 360, No. 1463, 2005, pp. 2067-208. doi:10.1098/rstb.2005.1744

[6] P. K, Thornton, P. G. Jones, T. M. Owiyo, R. L. Kruska, M. Herero, P. Kristjanson, A. Notenbaert, N. Bekele and Co-authors, "Mapping Climate Vulnerability and Poverty in Africa," Report to the Department for International Development, International Livestock Research Institute, Nairobi, 2006.
[7] IPCC, "Climate Change 2001: Impacts, Adaptation, and Vulnerability,” In: J. J. McCarthy, O. F. Canziani, N. A. Leary, D. J. Dokken and K. S. White, Eds., Contribution of Working Group II to the Third Assessment Report of the Intergovernmental Panel on Climate Change, Cambridge University Press, Cambridge, 2001, 1032 Pages.

[8] United Republic of Tanzania-URT, "Strategies for Addressing Negative Effects of Climate Change in Food Insecure Areas in Tanzania,” Research Report, Ministry of Agriculture Food Security and Cooperatives, Dar es Salaam, 2008.

[9] S. Agrawala, A. Moehder, A. Hemp, M. Van Aalst, S. Hitz, J. Smith,, H. Meena, S. Mwakifwamba, T. Hyera and O. Mwaipopo, "Development and Climate Change in Tanzania: Focus on Mount Kilimanjaro,” OECD, Paris, 2003.

[10] United Republic of Tanzania-URT, "State of the Environment Report-2008,” Division of Environment, Vice President's Office, Dar es Salaam, 2008, 292 Pages.

[11] United Republic of Tanzania-URT, "National Adaptation Programme of Action (NAPA)," Division of Environment, Vice President's Office, Dar es Salaam, 2007.

[12] United Republic of Tanzania-URT, "Initial National Communication under the United Nations Framework Convention on Climate Change (UNFCCC),” Vice President's Office, Dar es Salaam, 2005.

[13] P. Z. Yanda, R. Y. M. Kangalawe and R. J. Sigalla, “Climatic and Socio-Economic Influences on Malaria and Cholera Risks in the Lake Victoria Region of Tanzania,” ICIFAI Journal of Environmental Economics, Vol. 4, No. 3, 2006, pp. 44-70.

[14] M. K. Mwandosya, "Report to Plenary Session of the United Nation High Level Meeting on Adaptation to Climate Change,” Permanent Mission of the United Republic of Tanzania to the United Nation, Dar es Salaam, 2007.

[15] H. Mongi, A. Majule and J. G. Lyimo, "Vulnerability Assessment of Rain Fed Agriculture to Climate Change and Variability in Semi-Arid Tanzania," African Journal of Environmental Science and Technology, Vol. 4, No. 6, 2010, pp. 371-381.

[16] United Republic of Tanzania-URT, “Singida Region Socio-Economic Profile,” National Bureau of Statistics, Dar es Salaam and Regional Commissioner's Office, Singida, 2005.

[17] M. A. Lema and A. E. Majule, "Impacts of Climate Change, Variability and Adaptation Strategies on Agriculture in Semi Arid Areas of Tanzania: The Case of Manyoni District in Singida Region, Tanzania,” African Journal of Environmental Science and Technology, Vol. 3, No. 8, 2009, pp. 206-218.

[18] United Republic of Tanzania-URT, "Population and Housing Census, 2002," National Bureau of Statistics, Dar es Salaam, 2002.

[19] United Republic of Tanzania-URT, "Shinyanga Region Socio-Economic Profile,” The Planning Commission, Dar es Salaam and Regional Commissioner's Office, Shinyanga, 1999. 
[20] J. Andresen, J. Olson and P. Yanda, "The Effects of Climate and Land Use Change on Climate and Farming Systems in Tanzania,” Paper Presented at the Climate Land Interaction Project Policy Workshop, Dar es Salaam, 2008.

[21] G. Fischer, K. Frohberg, M. L. Parry and C. Rosenzweig, "Climate Change and World Food Supply, Demand and Trade: Who Benefit, Who Loses?” Global Environmental Change, Vol. 4, No. 1, 1994, pp. 7-23. doi:10.1016/0959-3780(94)90018-3

[22] R. Leemans and B. Eickhout, "Another Reason for Concern: Regional and Global Impacts on Ecosystems for Different Levels of Climate Change," Global Environmental Change, Vol. 14, No. 3, 2004, pp. 219-228. doi:10.1016/j.gloenvcha.2004.04.009

[23] L. Hein, M. J. Metzger and R. Leemans, "The Local Impacts of Climate Change in the Ferlo, Western Sahel," Climatic Change, Vol. 93, No. 3-4, 2009, pp. 465-483. doi:10.1007/s10584-008-9500-3

[24] T. Hussien, B. B. Mishra and H. Gebrekidan, “A New Parasitic Weed (Alectra vogelii) Similar to Striga on Groundnut in Ethiopia,” Tropical Science, Vol. 46, No. 3, 2006, pp. 139-140. doi:10.1002/ts.68

[25] R. Y. M. Kangalawe, "Climate Changes and Its Impact in Agricultural Sector in Tanzania” Paper Presented at the Technical Meeting on Capacity Building on Environmental Issues in Agriculture Sector,, Dar es Salaam, 2009.

[26] D. Olago, M. Marshall, S. Wandiga, M. Opondo, P. Yanda, R. Kangalawe, A. Githeko, T. Downs, A. Opere, R. Kabumbuli, E. Kirumira, L. Ogallo, P. Mugambi, E. Apindi, F. Githui, J. Kathuri, L. Olaka, R. Sigalla, R. Nanyunja, T. Baguma and P. Achola, "Climatic, SocioEconomic, and Health Factors Affecting Human Vulnerability to Cholera in the Lake Victoria Basin, East Africa,” Ambio, Vol. 36, No. 4, 2007, pp. 350-358. doi:10.1579/0044-7447(2007)36[350:CSAHFA]2.0.CO;2

[27] S. O. Wandiga, M. Opondo, D. Olago, A. Githeko, T. Downs, P. Z. Yanda, R. Y. M. Kangalawe, R. Kabumbuli, A. Opere, F. Githui, J. Kathuri, L. Olaka, E. Apindi, M. Marshall, L. Ogallo, P. Mugambi, E. Kirumira, R. Nanyunja, T. Baguma, R. Sigalla and P. Achola, "Vulnerability to Epidemic Malaria in the Highlands of Lake Victoria Basin: The Role of Climate Change/Variability, Hydrology, Health and Socio-Economic Factors," Climate Change, Vol. 99, No. 3-4, 2010, pp. 473-497. doi:10.1007/s10584-009-9670-7

[28] Y. T. Maina and N. E. S. Lale, "Effect of Seasonal Variation in Temperature and Humidity on the Development of Callosobruchus maculatus and the Efficacy of Neem Seed Oil Applied for Its Management in the Nigerian Sudan Savanna,” Tropical Science, Vol. 46, No. 1, 2006, pp. 50-54. doi:10.1002/ts.32

[29] R. Y. M. Kangalawe, E. T. Liwenga and A. E. Majule, "The Dynamics of Poverty Alleviation Strategies in the
Changing Environments of the Semiarid Areas of Sukumaland,” Tanzania. Research Report Submitted to REPOA, Dar es Salaam, 2007.

[30] R. Y. M. Kangalawe, D. G. Mwamfupe and M. J. Mbonile, "Land Management Systems and Their Environmental Impacts in the Usangu Plains, Tanzania," Journal of the Geographical Association of Tanzania, Vol. 32, 2007, pp. 15-32.

[31] R. Y. M. Kangalawe and E. T. Liwenga, "Livelihoods in the Wetlands of Kilombero Valley in Tanzania: Opportunities and Challenges to Integrated Water Resource Management," Physics and Chemistry of the Earth, Vol. 30, No. 11-16, 2005, pp. 968-975. doi:10.1016/j.pce.2005.08.044

[32] W. O. Siyanbola, F. A. Adesina, D. A. Pelemo, F. O. Oketola, L. O. Ojo and A. O. Adegbulugbe, "Towards Global Climate Change Mitigation: Assessment of an Afforestation Option for Nigeria," The Environmentalist, Vol. 22, No. 1, 2002, pp. 83-92. doi:10.1023/A:1014528326762

[33] M. D. Abdus-Salam and T. Noguchi, "Impact of Human Activities on Carbon Dioxide $\left(\mathrm{CO}_{2}\right)$ Emissions: A Statistical Analysis," The Environmentalist, Vol. 25, No. 1, 2005, pp. 19-30. doi:10.1007/s10669-005-3093-4

[34] R. Y. M. Kangalawe, C. Christiansson and W. Östberg, "Changing Land-Use Patterns and Farming Strategies in the Degraded Environment of the Irangi Hills, Central Tanzania,” Agriculture, Ecosystem and Environment, Vol. 125, No. 1-4, 2008, pp. 33-47.

doi:10.1016/j.agee.2007.10.008

[35] R. Y. M. Kangalawe, "Changing Land-Use Patterns in the Irangi Hills, Central Tanzania: A Study of Soil Degradation and Adaptive Farming Strategies," PhD Dissertation No. 22, Department of Physical Geography and Quarternary Geology, Stockholm University, Stockholm, 2001.

[36] C. A. Scott, "Facing Environmental Degradation in the Aravalli Hills, India,” In: A. C. Millington and K. Pye, Eds., Environmental Change in Drylands: Biogeographical and Geomorphological Perspectives, John Wiley \& Sons, Chichester, 1994, pp. 413-426.

[37] R. Y. M. Kangalawe, A. E. Majule and E. K. Shishira, "Land-Use Dynamics and Land Degradation in Iramba District, Central Tanzania,” Organisation for Social Science Research in Eastern and Southern Africa, Addis Ababa, 2005.

[38] C. G. Mung’ong'o, “Social Processes and Ecology in the Kondoa Irangi Hills. Central Tanzania” Meddelanden Series B93, Department of Human Geography, Stockholm University, Stockholm, 1995.

[39] R. Y. M. Kangalawe, E. T. Liwenga, R. Kabumbuli and M. K. Walingo, "Livelihood Diversification and Implications on Poverty and Environment in the Lake Victoria Basin,” African Journal of Environmental Science and Technology, Vol. 2, No. 10, 2008, pp. 272-281. 